\title{
RADIOLYTIC AND CHEMICAL STABILITY OF PURE HYDROCARBONS
}

\author{
by \\ Burton P. Dennis*
}

Apri1 1961

\begin{abstract}
* Presert address:
Anderson Chemical Div. Stauffer Chemical Co.

Weston, Michigan
\end{abstract}

E. I. du Pont de Nemours \& Co.

Explosives Department - Atomic Energy Division

Technical Division - Savannah River Laboratory

Printed for

The United States Atomic Energy Commission

Contract $\mathrm{AT}(07-2)-1$ 


\section{DISCLAIMER}

This report was prepared as an account of work sponsored by an agency of the United States Government. Neither the United States Government nor any agency Thereof, nor any of their employees, makes any warranty, express or implied, or assumes any legal liability or responsibility for the accuracy, completeness, or usefulness of any information, apparatus, product, or process disclosed, or represents that its use would not infringe privately owned rights. Reference herein to any specific commercial product, process, or service by trade name, trademark, manufacturer, or otherwise does not necessarily constitute or imply its endorsement, recommendation, or favoring by the United States Government or any agency thereof. The views and opinions of authors expressed herein do not necessarily state or reflect those of the United States Government or any agency thereof. 


\section{DISCLAIMER}

Portions of this document may be illegible in electronic image products. Images are produced from the best available original document. 


\begin{abstract}
The tendency of various classes of pure hydrocarbons to form zirconlum-complexing ligands during chemical or radiolytic degradation was evaluated. Olefins and aromatic-cycloparafins (mixed type) formed the most ligands and normal paraffins the fewest.
\end{abstract}




\section{CONTENTS}

$\underline{\text { Page }}$

Introduction

Summary $\quad 4$

Discussion $\quad 5$

Experimental Methods 5

Criterion for Stability 5

Degradation Conditions 5

Post-Degradation Washes 6

Results 6

Comparative Stabilities of Pure Hydrocarbons 6

Degradation of Mixtures of Pure Hydrocarbons 8

"Z Test" Evaluation 10

Bibliography 11

\section{LIST OF TABLES AND FIGURES}

$\underline{T a b l e}$

I Stabilities of Pure Hydrocarbons 7

II Stabilities of Mixtures of Pure Hydrocarbons 8

II Precision of the "Z Test" 10

Figure

1 Comparative Stabilities of Mixtures 9 


\title{
RADIOLYTIC AND CHEMICAL STABILITY OF PURE HYDROCARBONS
}

\author{
INTRODUCTION
}

In processing irradiated fuels by the Purex solvent extraction process, components of the kerosene diluent degrade to form ligands that complex certain of the fission products. (1,2) These ligands are not removed by conventional caustic and acid washes, but remain to cause poor removal of fission products from the desired end streams, to cause high losses of products, and to necessitate frequent recycling. $(1,3-6)$

Prior studies of the stabilities of various diluents and of specific types of hydrocarbons showed that normal paraffins were probably superior in chemical stability to any other types of hydrocarbons. $(1,7)$ The reported chemical stability of olefins and isoparaffins was poor and that of aromatics was varied. $(7-10)$ Very little was reported about the relative stability of various compounds believed to be present in a kerosene type diluent.

The present work was undertaken to provide a more comprehensive survey of the relative stabilities of various types of pure hydrocarbons. Knowledge of the stability of pure isomers was expected to simplify the problem of studying the degradation of the various mixtures that are proposed or used as Purex diluents.

\section{SUMMARY}

The chemical and radiolytic degradation of 21 high purity hydrocarbons in the molecular weight range of kerosene indicated that olefins and certain aromatic hydrocarbons are major precursors of zirconium ligands. The aromatic-cycloparaffins (mixed type), tetrahydronapthalene and indan, and the olefins, l-undecene, l-dodecene, and l-hexadecene, were highly unstable to the degradation procedure as measured by zirconium retention, or " $Z$ " numbers(i1). In addition, tetrahydronapthalene, indan, and l-hexadecene formed stable emulsions during the post-degradation washes. The instability of mixtures of 1 -dodecene and $n$-dodecane was a direct function of the concentration of l-dodecene. The stabilities of mixtures of aromatic-cycloparaffins (mixed type) and $n$-dodecane were not simple functions of the aromatic content, and in the case of $n$-dodecane - indan mixtures the results were completely anomalous. Dilute mixtures of indan in n-dodecane were as stable as pure n-dodecane.

The alkylbenzenes tested ranged from stable to moderately unstable. The position of the alkyl groups on the benzene ring had no significant effect upon the stability of these compounds. The aromatic compounds were highly colored after degradation and, in general, the intensity of color increased with increasing zirconium retention. 
The compounds tested in the isoparaffin, cycloparafin, and normal paraffin classes were comparatively stable. A synthetic kerosene made from the relatively stable pure compounds was also stable.

\section{DISCUSSION}

\section{EXPERIMENTAL METHODS}

\section{CRITERION FOR STABILITY}

The relative stablilties of the diluents and pure hydrocarbons tested

in this investigation were determined by means of the "z test". (11)

In this test the degraded and washed diluent is equilibrated with a solution of zirconlum tracer. The concentration of zirconium retained by the diluent after it is scrubbed with $3 \mathrm{M} \mathrm{HNO}_{3}$ is representative of the solvent quality and is expressed as the " $Z$ " number. The " $Z$ " number is the number of moles of zirconium retained per billion liters of solvent.

"Ultrasene*", a refined kerosene used as a Purex diluent at the Savannah River Plant, and n-dodecane were employed as controls in all of the degradation tests.

\section{DEGRADATION CONDITIONS}

Conditions for chemical and radiolytic degradation were chosen such that the extent of Iigand formation in "Ultrasene" as determined by the "Z test" would be approximately the same for both types of degradation. The samples were degraded chemically by contacting approximately $2 \mathrm{ml}$ of each with an equal volume of $4 \mathrm{M} \mathrm{HNO}_{3}-0.1 \mathrm{M}$ $\mathrm{HNO}_{2}{ }^{*}$ for 7 days at $70^{\circ} \mathrm{C}$. The test materials were contained in 15-mm-OD "Pyrex" tubes loosely stoppered with plugs of "Pyrex" or "Teflon".

Radiolytic degradation was accomplished by exposure to the level of $10^{7}$ rep $\pm 10 \%$ as measured by ceric sulfate dosimetry in a beta-gamma source from Irradiated fuel elements.***

*Atlantic Refining Company

* The $4 \mathrm{M} \mathrm{HNO}_{3}-0.1 \mathrm{M} \mathrm{HNO}_{2}$ solution was prepared by the addition of $8 \mathrm{M} \mathrm{HNO}_{3}$ to an equal volume of a $0.2 \mathrm{M} \mathrm{NaNO} \mathrm{Na}_{2}$ solution and adjusted if necessary. The $\mathrm{NO}_{2}^{-}$concentration was determined by the addition of an excess of standard $0.05 \mathrm{~N}$ ceric ammonium sulfate to the $\mathrm{HNO}_{3}-\mathrm{NaNO}_{2}$ solution, followed by titration of the excess ceric sulfate with standard $0.1 \mathrm{~N}$ ferrous ammonium sulfate.

***The extent of chemical degradation occurring during radiolysis was not determined but was low. In a typical irradiation, the samples were Irradiated to $2.5 \times 10^{6} \mathrm{rep} / \mathrm{hr}(8.4$ watt-hr/l) for 4 hours and reached a maximum temperature of $60 \pm 2^{\circ} \mathrm{C}$. 
Approximately $2 \mathrm{ml}$ of the sample was sealed in 15-mm-OD "Pyrex" tubes in contact with an equal volume of $4 \mathrm{M} \mathrm{HNO}_{3}-0.1 \mathrm{M} \mathrm{HNO}_{2}$. The residual volume, approximately $15 \mathrm{cc}$, contained air.

\section{POST-DEGRADATION WASHES}

After removal of the aqueous phase, the organic phase was given single washes successively with equal volumes of distilled water, IM $\mathrm{NaOH}$, distilled water, $1 \mathrm{M} \mathrm{HNO}_{3}$, and then repeated washes with distilled water until the washings were neutral. After the samples were washed they were made up to $30 \%$ tri-n-butyl phosphate with virgin TBP $(3)$ and the extent of ligand formation in the degraded component was measured by means of the "z test".

\section{RESULTS}

\section{COMPARATIVE STABILITIES OF PURE HYDROCARBONS}

The stabilities of 21 pure compounds were compared with those of "Ultrasene" and of $\mathrm{n}$-dodecane*. The compounds tested were the purest avallable; 19 were obtained from the National Bureau of Standards and 2 from Eastman Kodak Company. The compounds and their relative stabilities, as determined by the "Z test", are shown in Table I. In the normal, iso-, and cycloparaffin classes the tested compounds were stable toward both chemical and radiolytic degradation. The olefins and certain of the aromatic-cycloparaffins (mixed type) were highly unstable under the same conditions of degradation. These results agree with previous work except for the isoparaffins which previously were reported to be unstable. $(7,10)$ Two possible explanations of the differences in the results obtained with isoparaffins are: since the availability of $\mathrm{C}_{9}-\mathrm{C}_{15}$ isoparaffins of high isomeric purity is limited, the isoparaffins tested in this investigation may not be entirely representative of this class of compound; or, the isoparaffinic diluents tested in previous work may have contained significant amounts of unstable impurities, since commercial grades of diluents were tested.

Alpha-olefins were the least stable of the compound types tested. In addition to producing zirconium ligands, 1-hexadecene formed a stable emulsion during the caustic wash.

The tendency to form zirconium ligands was a function of the structure in pure aromatic compounds and varied over a wide range. The aromatic-cycloparaffins (mixed type), tetrahydronapthalene and indan, were the least stable of any of the aromatic compounds tested. Both

\footnotetext{
* "Olefin-free" n-dodecane obtained from Humphrey-Wlikinson and found to have stabilities identical to those of n-dodecane from the National Bureau of Standards.
} 
Stabllities of Pure Hyarocarbons (a)

$\underset{\text { Compound }}{\text { Class }}$

Normal Parafins $n$-Dodecane $n$-Dodecane $(e)$ Isoparafilins

$2,2,4,6,6$-Pen tame thy lhep tane 2,2, 4-Trime thylpentane $(f)$ 2, 3,5-Trime thylhexane

\begin{tabular}{|c|c|c|c|c|c|}
\hline \multicolumn{3}{|c|}{$\operatorname{Rad101yt1c}(c)$} & \multicolumn{3}{|c|}{ Chem1cal (d) } \\
\hline & Moderately & & & Moderately & \\
\hline ble & Unstable & Unstable & Stable & Unstable & Unstable \\
\hline
\end{tabular}

$\mathrm{x}-\mathrm{x}$

$\mathrm{x}-\mathrm{x}$

$\begin{array}{ll}x & x \\ x & x\end{array}$

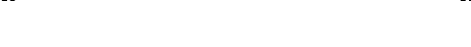

$\mathrm{x}-\mathrm{x}$

$\mathrm{x}-\mathrm{x}$

$\begin{array}{ll}\mathrm{x} & \mathrm{x} \\ \mathrm{x} & \mathrm{x}\end{array}$
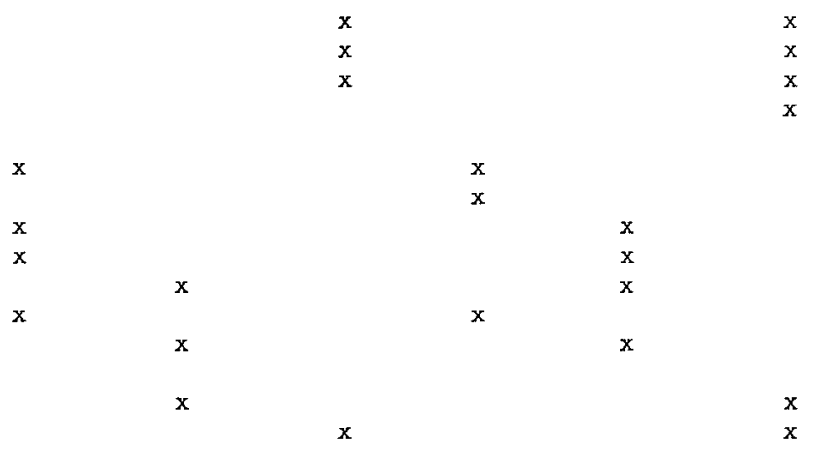

(a) Stability was divided into three classes according to the ratio, "z" no. of pure compound/" $z$ " no. of n-dodecane. The range for each group is as follows: stable, <2; moderately unstable, 2-8; very unstable, $>8$.

(b) From the National Bureau of Standards except where noted. Impurit1es cert1f1ed to be <0.2 mol $\%$.

(c) Irradiated to $10^{7}$ rep $\pm 10 \%$ in contact 1 th $4 \mathrm{M} \mathrm{HNO}_{3}-0.1 \mathrm{M} \mathrm{HNO}_{2}$.

(d) Contacted with $4 \mathrm{M} \mathrm{HNO}_{3}-0.1 \mathrm{M} \mathrm{HNO}_{2}$ for 7 days at $70^{\circ} \mathrm{C}$.

(e) Humphrey-W1lkinson "olef1n-free" n-dodecane. The n-dodecane used as a control in these tests.

(f) Eastman white label grade. 
compounds increased in density during degradation and formed emulsions with the post-degradation washes. The chemical and radiolytic stabilities of indan were comparable to those of the olefins. The alkyl benzenes ranged from stable to moderately unstable. The position of the alkyl groups on the benzene ring had no signiflcant effect on the stability of these compounds, which suggested that reactions of addition to the benzene ring, such as nitration, do not contribute significantly to the formation of zirconium ligands. The color of the aromatic compounds after degradation ranged from a light yellow to a very dark brown. In general, the " $\mathrm{"} \mathrm{number} \mathrm{increased}$ as the intensity of the color increased.

\section{DEGRADATION OF MIXTURES OF PURE HYDROCARBONS}

Stability tests on mixtures of pure hydrocarbons in $\mathrm{n}$-dodecane indicated that the stability of the $n$-dodecane may be reduced to that of "Ultrasene" by the presence of $0.25 \%$ of 1 -dodecene or a few per cent of naphthalene. Aliquots of $\mathrm{n}$-dodecane were spiked with small quantities of these two hydrocarbons to determine their effect on the stability of the resulting mixture. After degradation and the usual. post-degradation washes, the concentration of zirconium ligands was measured by the " $Z$ test". The results are shown in Table II. The dilute solution of the alpha-olefin in n-dodecane is comparable to "Ultrasene" in being moderately unstable.

\section{TABLE II}

Stabilities of Mixtures of Pure Hydrocarbons (a)

\begin{tabular}{|c|c|}
\hline & Mod \\
\hline
\end{tabular}

$0.25 \%$ 1-Dodecene in $\mathrm{n}$-dodecane

$5 \%$ Naphthalene - 95\% n-dodecane

$23 \% \mathrm{n}$-Dodecane

$16 \% 2,2,4,6,6$-Pen tame thylhep tane

$33 \%$ n-Butylcyclohexane

$10 \%$ trans-Decahydronapthalene

16\% Isobutylbenzene

"Ultrasene"

n-Dodecane $\mathrm{x}$

$\mathrm{X}$

$\mathrm{x}$

$\mathrm{X}$

$\mathrm{x}$

(a) Stability was divided into three classes according to the ratio, " $Z$ " no. of pure compound/" $Z$ " no. of $n$-dodecane. The range for each group is as follows: stable, <2; moderately unstable, 2-8; very unstable, $>8$. 
The stability of a synthetic kerosene, a mixture of five hydrocarbons of high purity, was comparable to that of the individual compounds in the mixture, and to that of $\mathrm{n}$-dodecane. The mixture was degraded to determine if there was any synergistic action between compounds that may promote zirconium ligand production. The five compounds were combined in the approximate concentrations that these compound types occur in the kerosene fraction of one representative sample of petroleum. (12) This mixture was radiolytically degraded and given the usual post-degradation washes and " $Z$ test". The data are shown in Table II.

The stabilities of mixtures of tetrahydronapthalene with n-dodecane, and of indan with $\mathrm{n}$-dodecane varied widely from those of 1 -dodecene $n$-dodecane mixtures. Although tetrahydronapthalene and indan both formed large amounts of zirconium ligands when degraded as pure compounds, concentrations in the range of 0 to $10 \mathrm{vol} \%$ of these two compounds in $\mathrm{n}$-dodecane had only minor effects upon the stabilities of the resulting mixtures. The stabilities of the tetrahydronapthalene mixtures were only slightly poorer than that of pure $n$-dodecane and the stabilities of the indan mixtures were comparable to that of $\mathrm{n}$-dodecane. This anomaly was not explained. The data obtained for these mixtures are shown in Figure 1 , together with the " $Z$ " numbers measured on degraded aliquots of the pure compounds.

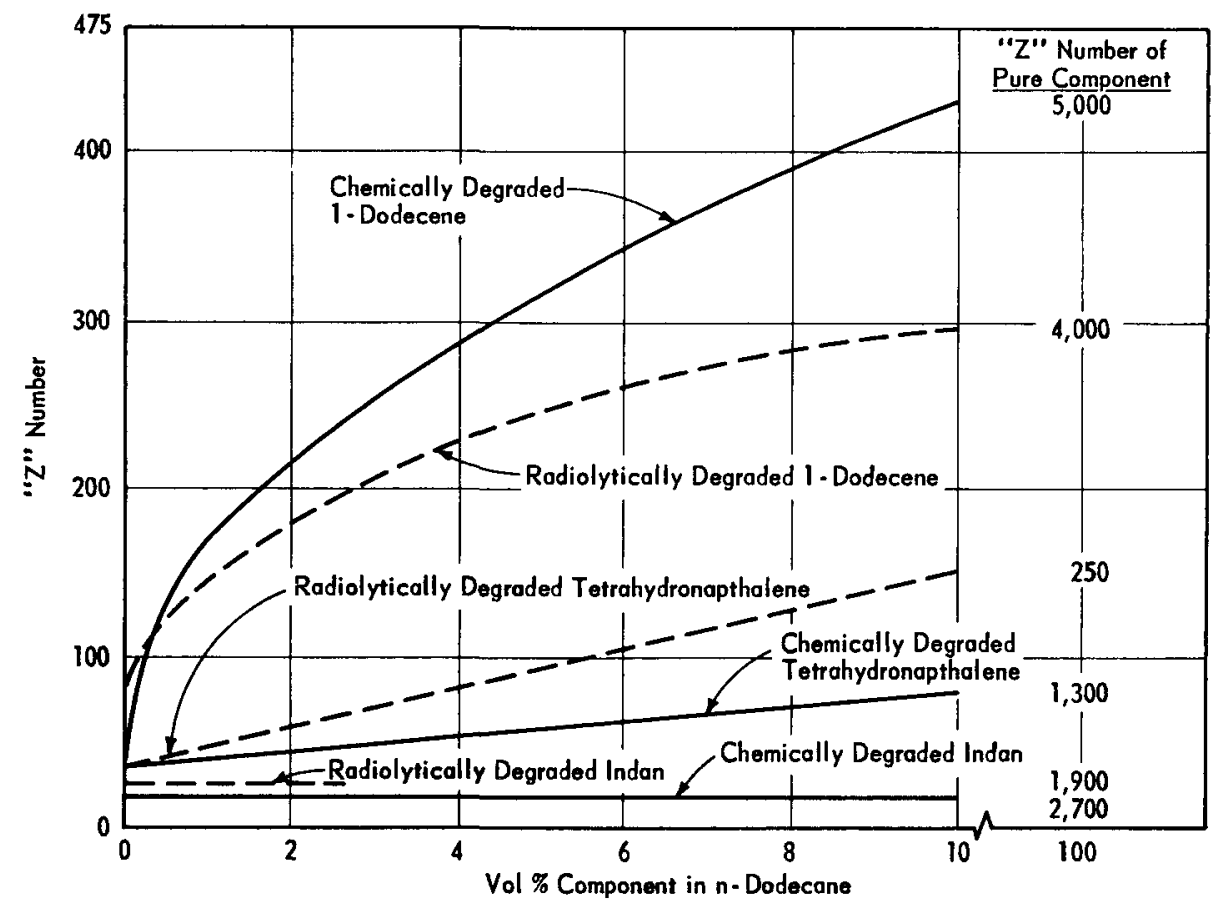

FIG. 1 COMPARATIVE STABILITIES OF MIXTURES 
"Z TEST" EVALUATION

An evaluation of the " $Z$ test" showed that the test distinguishes between diluents that are stable, moderately unstable, or highly unstable. The coefficlent of variation of the " $\mathrm{Z}$ test" was $20 \%$ for " $Z$ " numbers in the moderately unstable class. Precision data were determined on degraded n-dodecane, "Ultrasene", and 1-dodecene. One sample of each materlal was divided into several allquots and the aliquots were tested. The results of the tests are shown in Table III.

\section{TABLE III}

Precision of the "Z Test"

\begin{tabular}{|c|c|c|c|c|}
\hline Materlal & $\begin{array}{c}\text { No. of } \\
\text { Aliquots } \\
\end{array}$ & $\begin{array}{l}\text { Avg. " } Z \text { " } \\
\text { Number } \\
\end{array}$ & $\begin{array}{c}\text { 95\% Confidence } \\
\text { Limit for Individual } \\
\text { Determination } \\
\end{array}$ & $\begin{array}{c}\text { Coefficient } \\
\text { of Varlation, of }\end{array}$ \\
\hline n-Dodecane & 9 & 6.2 & \pm 5.8 & 41 \\
\hline "Ul trasene" & 9 & 28 & \pm 13 & 22 \\
\hline I-Dodecene & 8 & 2400 & \pm 940 & 17 \\
\hline
\end{tabular}

The data obtained confirmed the utility of the " $\mathrm{z}$ test" for screening diluents; however, the data also showed that considerable refinement would be required before the test could be used to distinguish between diluents within a given classification.

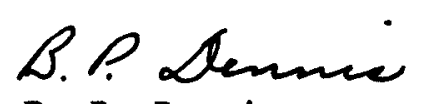

B. P. Dennis

Analytical Chemistry Division 


\section{BIBLIOGRAPHY}

1. Pollock, H. A Stable Diluent for Purex Process Extractants. E. I. du Pont de Nemours \& Co., Savannah River Laboratory, Aiken, S. C. AEC Research and Development Report DP-294, $7 \mathrm{pp}$. (June 1958).

2. Goode, J. H. "How Radiation Affects Organics in Solvent Extraction of Fuel". Nucleonics 15, No. 2, pp. 68-71 (1957).

3. Siddall, T. H., III, and H. Pollock. E. I. du Pont de Nemours \& Co., Savannah River Laboratory, Aiken, S. C. AEC Research and Development Report DP-290, $15 \mathrm{pp}$. (May 1958). (Confidential).

4. Swanson, J. I. The Stability of Purex Solvent to Radiation and Chemical Attack. General Electric Co., Hanford Atomic Products Operation, Richland, Washington. AEC Research and Development Report HW-38263, $32 \mathrm{pp}$. (May 1955) (declassified August 1959).

5. Knight, J. A., Jr. Radiation Chemistry of Organic Substances. Oak Ridge National Laboratory, Oak Ridge, Tennessee, Engineering Experiment Station, Georgia Institute of Technology, Atlanta, Georgia. AEC Research and Development Report AECU-4056, 38 pp. (January 31, 1959).

6. Wagner, R. M. and L. H. Towle. Radiation Stability of Organic Liquids. Semi-Annual Report No. 4 for July I to December 3I, 1958. Oak Ridge National Laboratory, Oak Ridge, Tennessee, Stanford Research Institute, Menlo Park, Cal1f. AEC Research and Development Report AECU-4054, 40 pp. (January 5, 1959).

7. Klopfenstein, R. K. Studies of the Behavior of the TBP-Kerosene Solvent in Uranlum Refining: Degradation of the Kerosene Diluent. National Lead Co. of Ohio, Cincinnati, Ohio. AEC Research and Development Report NLCO-769, 49 pp. (August 1958).

8. Moore, R. H. Investigation of Solvent Degradation Products in Recycled Uranium Recovery Plant Solvent. General Electric Company, Hanford Atomic Products Operation, Richland, Washington. AEC Research and Development Report HW-34502 (Rev.), 19 pp. (April 1955) (declassified February 1957).

9. Moore, R. H. Chemical Stability of Purex and Uranium Recovery Process Solvent. General Electric Co., Hanford Atomic Products Operation, Richland, Washington. AEC Research and Development Report HW-34501, 15 pp. (March 1955) (declassified July 1959). 
10. Ellerhorst, R. H., et al. "Solvent Degradation and Treatment Studies". Summary Technical Report for the Period October I, 1957 to December 31, 1957. National Lead Co. of Ohio, Cincinnat1, Ohio. AEC Research and Development Report NLCO-715, pp. 17-22 (February 1958) (declassifled February 1960).

11. Garrett, T. P., Jr. A Test for Solvent Qual1ty. E. I. du Pont de Nemours \& Co., Savannah River Laboratory, Aiken, S. C. AEC Research and Development Report DP-237, 16 pp. (August 1957).

12. Rossin1, F. D., B. J. Mair and A. J. Stre1ff. Hydrocarbons from Petroleum. New York: Reinhold Publishing Corp. 556 pp. $(1953)$. 